\title{
Maternal and perinatal characteristics and outcomes of pregnancies complicated with COVID-19 in Kuwait
}

Amal Ayed ${ }^{1}$, Alia Embaireeg², Asmaa Benawadh', Wadha Al-Fouzan³ ${ }^{3}$ Majdeda Hammoud ${ }^{4}$, Monif Al-Hathal ${ }^{5}$, Abeer Alzaydai ${ }^{6}$, Ashraf Ahmad ${ }^{1}$ and Mariam Ayed $^{7^{*}}$ (D)

\section{Abstract}

Background: The effect of SARS-CoV-2 infection in pregnant women and newborns is incompletely understood. Preliminary data shows a rather fluctuating course of the disease from asymptomatic or mild symptoms to maternal death. However, it is not clear whether the disease increases the risk of pregnancy-related complications. The aim of the study is to describe the maternal and neonatal clinical characteristics and outcome of pregnancies with SARS-CoV-2 infection.

Methods: In this retrospective national-based study, we analyzed the medical records of all pregnant women infected with SARS-CoV-2 and their neonates who were admitted to New-Jahra Hospital (NJH), Kuwait, between March 15th 2020 and May 31st 2020. During the study period and as part of the public health measures, a total of 185 pregnant women infected with SARS-CoV-2, regardless of symptoms, were hospitalized at NJH, and were included. Maternal and neonatal clinical manifestations, laboratory tests and treatments were collected. The outcomes of pregnancies included miscarriage, intrauterine fetal death (IUFD), preterm birth and live birth were assessed until the end date of the outcomes follow-up (November 10th 2020).

Results: A total of 185 pregnant women infected with SARS-CoV-2 were enrolled with a median age of 31 years (interquartile range, IQR: 27.5-34), and median gestational age at diagnosis of SARS-CoV2 infection was 29 weeks (IQR: 18-34). The majority (88\%) of these women had mild symptoms, with fever (58\%) being the most common presenting symptom followed by cough (50.6\%). At the time of the analysis, out of the 185, 3 (1.6\%) of the pregnant women had a miscarriage, 1 (0.54\%) had IUFD which was not related to COVID-19, 16 (8.6\%) had ongoing pregnancies and 165 (89\%) had a live birth. Only 2 (1.1\%) of these women developed severe pneumonia and required intensive care. A total of 167 neonates with two sets of twins were born with median gestational age at birth was 38 (IQR: 36-39) weeks. Most of the neonates were asymptomatic, and only 2 of them tested positive on day 5 by nasopharyngeal swab testing.

Conclusions: In this national-based study, most of the pregnant women infected with SARS-CoV-2 showed mild symptoms. Although mother-to-child vertical transmission of SARS-CoV-2 is possible, COVID-19 infection during pregnancy may not lead to unfavorable maternal and neonatal outcomes.

Keywords: SARS-CoV-2, COVID-19, Pregnant women, Neonates, Clinical features

\footnotetext{
* Correspondence: mariam.ayed@hsc.edu.kw

${ }^{7}$ Neonatal Department, Farwaniya Hospital, Subah An Nasser, 81400 Kuwait City, Kuwait

Full list of author information is available at the end of the article
}

(c) The Author(s). 2020 Open Access This article is licensed under a Creative Commons Attribution 4.0 International License, which permits use, sharing, adaptation, distribution and reproduction in any medium or format, as long as you give appropriate credit to the original author(s) and the source, provide a link to the Creative Commons licence, and indicate if changes were made. The images or other third party material in this article are included in the article's Creative Commons licence, unless indicated otherwise in a credit line to the material. If material is not included in the article's Creative Commons licence and your intended use is not permitted by statutory regulation or exceeds the permitted use, you will need to obtain permission directly from the copyright holder. To view a copy of this licence, visit http://creativecommons.org/licenses/by/4.0/ The Creative Commons Public Domain Dedication waiver (http://creativecommons.org/publicdomain/zero/1.0/) applies to the data made available in this article, unless otherwise stated in a credit line to the data. 


\section{Background}

In late December of 2019, a novel coronavirus (SARS$\mathrm{CoV}-2)$ emerged in the Chinese city Wuhan was identified among a cluster of pneumonia cases [1]. The outbreak of coronavirus disease (COVID-19) rapidly spread to become a global pandemic as declared by the World Health Organization in March 2020 [1-3]. This remarkable widespread SARS-CoV-2 reflects a new public health crisis [4].

SARS-CoV-2 is a member of the Coronavirus family, and other pathogens from this family have inflicted a range of viral infections, including Middle East Respiratory Syndrome (MERS) and Severe Acute Respiratory Syndrome (SARS) [5]. The main route of transmission is through respiratory droplets and direct contact. While the spectrum of the disease severity ranges from mild to critical, most are mild. Most of the fatal cases occurred in patients with advanced age or underlying comorbidities [6]. However, to this date, the SARS-CoV-2 mortality rate is greater than MERS and SARS combined and has a global Case Fatality Rate of about 6.4\% [1].

Although it is known that pregnant women have a reduced immunity [5], and they are at risk for COVID-19 infection during the current pandemic, it is not clear how the disease manifestation would be different in pregnant women from non-pregnant women. It is known that the body's immune system and response to viral infections might be changed due to pregnancy, which explains the cause of more severe symptoms [7]. However, some previous studies have shown that pregnant women are not more susceptible to SARS-CoV-2 than non-pregnant women [8-11]. Considering the severity of disease, limited data suggest that the pregnant women may present with severe symptoms that include hypoxia, hypotension, electrolyte disturbances, and placental hypo perfusion, which can provoke fetal distress, preterm labor, miscarriage, or fetal death [12-18].

Preliminary evidence from the diseases caused by the H1N1 virus (H1N1 influenza) and other coronaviruses (SARS and MERS) have suggested that pregnant women are more likely to have severe manifestations of the disease, morbidity, and mortality as compared to nonpregnant women [19-22]. Moreover, some studies have shown increased risk of these critical illness with the increased duration of pregnancy [23-25].

To date, information about the different routes (transplacental, perinatal, intrapartum, and postnatal) and risks of transmission of COVID-19 to newborn infants is based on case series [13]. In consideration of the fact that SARS-CoV-2 is a respiratory virus, the risk of vertical transmission is supposed to be very low or absent. This supposition is supported by the evidence that no vertical transmission was detected in other members of the coronavirus family (SARS and MERS) [19].
The risk of perinatal transmission of SARS-CoV-2 is unknown. Additionally, since the risk of postnatal transmission remains to be elucidated, it is debatable whether the newborn should be immediately separated from the COVID-19 positive mother [8]. A study comprised of outcomes of 7 newborns concluded that COVID-19 positive mother does not cause unfavorable outcomes in their neonates, but it is required to separate newborns from mothers right away to avoid potential threats of SARS-CoV-2 infection [26]. In another study, contrary to the previous one, it is concluded that separation may not prevent infection, and early separation might increase neonatal risk of pneumonia [27]. However, the severity of postnatally acquired disease in the newborn is unknown. A case series of 10 neonates born to COVID19 positive mothers reported no evidence of vertical transmission of SARS-CoV-2. However, it suggested that perinatal SARS-CoV-2 infection may cause fetal distress, premature labor, respiratory distress, thrombocytopenia accompanied by abnormal liver function, and even death among neonates [12].

We believe that the information on outcomes of such pregnancies could continuously update guidance and management procedures for COVID-19 positive pregnant mothers and their neonates. Therefore, the study aimed at describing the maternal as well as neonatal clinical features and outcome of pregnancies complicated with SARS-CoV-2 infection.

\section{Methods}

Study design

We performed a retrospective national-based analysis of medical records from all SARS-CoV-19 positive pregnant women and their neonates who were admitted to New-Jahra Hospital, Kuwait between March 15th, 2020 and May 31st, 2020, and the outcomes were assessed till the end date of follow-up (November 10th, 2020). New Jahra hospital was designated as a national hospital for the management of COVID-19 infected pregnant women and neonates born to infected mothers in Kuwait. During the study period, as part of Kuwait's national COVID- 19 policy, all pregnant women were tested if they had SARS-CoV-2 symptoms or had been in contact with infected patients. Moreover, all confirmed COVID-19 positive pregnant women were admitted to the maternity department regardless of symptoms or gestational age at diagnosis of SARS-CoV-2 infection for at least 14 days or till resolution of symptoms. Patient management was based on local and international protocols (Additional file 1).

The study was approved by the Ethics Committee of the Ministry of Health of Kuwait (2020/1420). 


\section{Patient selection criteria}

We enrolled all pregnant women admitted to the maternity department due to SARS-CoV-2 infection, as confirmed by real-time reverse transcriptase-polymerase chain reaction (RT-PCR) assay of nasopharyngeal swab specimens (Cobas 6800 Systems, Roche, Switzerland)/ (TaqPath, Thermo-Fisher Scientific, USA). Patients who had equivocal or negative testing results were excluded from the study.

\section{Assessment of neonates}

A little was known about the risk of postnatal acquired COVID-19 disease during the early pandemic. However, our national policy recommended that all neonates born to SARS-CoV-2 infected mother should be assessed by the neonatal team after birth. They were isolated immediately and admitted to a designated neonatal intensive care unit. All neonates born to SARS-CoV-2 positive mothers were admitted to a negative pressure isolated single room, cared for by health care providers wearing full personal protective equipment, and were fed either breast milk or artificial formula. Moreover, nasopharyngeal swab testing was performed for all neonates on day 5 and then on day 14. Since June 2020, the national policy has been updated and does not recommend immediate separation of the newborn and encourage immediate skin to skin contact if mother and baby are well.

\section{Data collection}

Maternal and neonatal data were extracted from the electronic medical records or medical charts using a standardized data collection sheet. For maternal data, we recorded the information on gestational age at diagnosis of SARS-CoV-2, parity (nulliparous or multiparous), pre-existing medical condition (i.e., including hypertension, diabetes, bronchial asthma, hypothyroidism, and autoimmune diseases) and presenting symptoms prior to admissions, such as fever, sore throat/ nasal or sinus congestion, cough/chest pain, vomiting/diarrhea, and fatigue/myalgia). Information on current pregnancy was also collected, including gestational diabetes, pregnancyinduced hypertension, pre-eclampsia, and multiple pregnancies. We collected the laboratory and chest $\mathrm{x}$-ray results upon admission to the hospital. Information on patient-specific therapies, such as antenatal steroids for lung maturation, administration of antibiotics, antivirals, and thromboprophylaxis (i.e. low molecular weight heparin) was also collected. For patients admitted to intensive care unit, we obtained data on maximum respiratory support (i.e. intubation and mechanical ventilation), acute respiratory distress syndrome (ARDS) as defined according to the Berlin criteria and duration of ventilation [28].
For neonatal data, we collected gestational age at delivery, mode of delivery, birth weight, 1- and 5-min Apgar score, and the results of nasopharyngeal swabs. Data entry and quality were checked and reviewed independently by two investigators ( $\mathrm{AE}$ and $\mathrm{AB}$ ).

We defined gestational age as the number of weeks calculated according to the last normal menstrual period or expected date of delivery according to an early ultrasound scan. Gestational diabetes was defined as high blood sugar (glucose) using the Oral Glucose Tolerance Test as a screening method (fasting blood sugar $\geq 5.1$ $\mathrm{mmol} / \mathrm{L}$ or $1 \mathrm{~h}$ postprandial $\geq 10 \mathrm{mmol} / \mathrm{L}$ or $2 \mathrm{~h}$ postprandial $\geq 8.5 \mathrm{mmol} / \mathrm{L}$ ) that developed during pregnancy and usually disappeared after giving birth. Preeclampsia was defined as new onset of hypertension (over 140 $\mathrm{mmHg}$ systolic or over $90 \mathrm{mmHg}$ diastolic) after 20 weeks of pregnancy and significant proteinuria. Pregnancy-induced hypertension (PIH) was defined as a new hypertension presenting after 20 weeks of pregnancy without significant proteinuria.

\section{Statistical analysis}

We reported continuous variables as mean \pm standard deviation (SD) or median (interquartile range [IQR]) and categorical variables as number and percentage. Statistical analysis was performed using STATA/IC 14 software (STATA Corp, College Station, Texas).

\section{Results}

During the study period, 185 pregnant women were identified with confirmed SARS-CoV-2 infection with a median age of patients was 31 years (IQR: 27.5-34), and $19.5 \%$ were nulliparous. The majority of patients (91\%) had no pre-existing medical comorbidities, 19 (10.3\%) patients had gestational diabetes, and $4(2.3 \%)$ had PIH. The median gestational age at diagnosis of SARS-CoV-2 was 29 weeks (IQR: 18 to 34 ), and half of the women were in their 3rd trimester. Additionally, the majority of the patients $(88.6 \%)$ were symptomatic. The most common symptom was fever in 105 (58\%) patients, followed by cough in $90(50.6 \%)$ patients, and the median duration of symptoms prior to hospital admission was 2 days (IQR:1-4). Table 1 presents the characteristics of pregnant women with confirmed SARS-CoV-2 infection.

The laboratory findings of pregnant women are shown in Table 2. Seventeen (9.2\%) of the pregnant patients had leukopenia, and 29 (15.7\%) had lymphopenia. Fortysix (37\%) patients had elevated C-reactive protein and 12 (11\%) had elevated procalcitonin. Elevated alanine aminotransferase (ALT), aspartate aminotransferase (AST), D-dimer and lactate dehydrogenase (LD) were observed in $24.2 \%, 11.2,10$ and $42 \%$, respectively of the patients in which the test was ordered. Eight (15.4\%) patients had a chest $\mathrm{x}$-ray diagnosis of pneumonia. 
Table 1 Characteristics of pregnant women with confirmed SARS-CoV-2 infection

\begin{tabular}{|c|c|}
\hline Characteristic & Total number $=185(\%)$ \\
\hline Age, years (median, IQR) & $31(27.5-34)$ \\
\hline \multicolumn{2}{|l|}{ Parity: } \\
\hline Nulliparous & $36(19.5 \%)$ \\
\hline Multiparous & $149(80.5 \%)$ \\
\hline \multicolumn{2}{|l|}{ Pre-existing medical disease: } \\
\hline Hypothyroidism & $7(3.9 \%)$ \\
\hline Bronchial Asthma & $4(2.2 \%)$ \\
\hline Chronic diabetes & $1(0.5 \%)$ \\
\hline $\begin{array}{l}\text { Others (rheumatoid arthritis } n=1 \text {, anxiety } n=1 \text {, peptic ulcer }=1, n=1 \text {, Crohn's disease, } n=1 \text {, beta-thalassemia } \\
\text { minor }=1 \text { ) }\end{array}$ & $5(2.8 \%)$ \\
\hline Missing data & $5(2.8 \%)$ \\
\hline Gestational diabetes & $19(10.3 \%)$ \\
\hline Preeclampsia & $4(2.3 \%)$ \\
\hline Gestational Age at diagnosis of SARS-CoV-2 infection weeks (median, IQR) & $29(18-34)$ \\
\hline \multicolumn{2}{|l|}{ Trimester: } \\
\hline 1st (less than 12 weeks) & $21(11.4 \%)$ \\
\hline 2nd (13-27 weeks) & $64(34.6 \%)$ \\
\hline $3 r d$ (> 28 weeks) & $95(51.3 \%)$ \\
\hline Postpartum & $5(2.7 \%)$ \\
\hline Multiple pregnancies & $2(1.1 \%)$ \\
\hline Symptoms: & 165 \\
\hline Fever & $105(58 \%)$ \\
\hline Cough & $90(50.6 \%)$ \\
\hline Loss of smell & $10(5.8 \%)$ \\
\hline Sore throat /rhinorrhea & $42(24.3 \%)$ \\
\hline Malaise/Fatigue & $26(15.1 \%)$ \\
\hline Chest pain/shortness of breath & $22(12.8 \%)$ \\
\hline Vomiting/diarrhea & $11(6.4 \%)$ \\
\hline Duration of symptoms prior to admission, days & $2(1-4)$ \\
\hline Asymptomatic & $21(11.3 \%)$ \\
\hline
\end{tabular}

Maternal treatment and outcomes are shown in Table 3. Two (1.1\%) patients required critical care for worsening respiratory conditions. The majority (97.3\%) of the patients received Oseltamivir, and only $2(1.1 \%)$ received Lopinavir-ritonavir. Ceftriaxone was given in $24.3 \%$ of the patients, and $96.7 \%$ received low molecular weight heparin.

Two patients requiring Intensive care unit (ICU) were at 37- and 38-weeks' gestation. One developed hypoxia (oxygen saturation, 88\%) and shortness of breath due to worsening pneumonia necessitating intubation and emergency caesarian-section, while the second patient had worsening respiratory condition $24 \mathrm{~h}$ post-delivery (Table S1). None of them required extracorporeal membrane oxygenation (ECMO), and both got discharged subsequently. At the time of follow-up, all of the patients were discharged, and the median duration of hospital stay was 15 days (IQR:14-22).

Pregnancy and neonatal outcomes are shown in Table 4 . At the time of the analysis, out of the 185 , $16(8.6 \%)$ of the women had ongoing pregnancies, $165(89 \%)$ had a live birth, 3 (1.6\%) had a miscarriage, and $1(0.54 \%)$ had intrauterine fetal death, which was not related to COVID-19. Details of the cases resulting in spontaneous miscarriages are shown in Tables S2.

The median gestational age at birth was 38 (IQR: 3639) weeks. Of the 165 women who had given birth, 44 (26.6\%) gave birth preterm. One preterm birth at 27 weeks was iatrogenic (due to pathological cardiotocography) and one at 31 weeks due to premature rupture of membrane. Forty-two women gave birth between 33 and 
Table 2 Laboratory and radiological characteristics of pregnant women

\begin{tabular}{|c|c|c|}
\hline \multirow[t]{2}{*}{ Laboratory test } & \multicolumn{2}{|c|}{ Laboratory value } \\
\hline & $\bar{N}$ & $\begin{array}{l}\text { Median (IQR) } \\
\mathrm{N}(\%)\end{array}$ \\
\hline White blood count (WBC) $\times 10^{9}$ per L & 185 & $6.7(5.6-9.2)$ \\
\hline WBC Less than 4 & & $17(9.2 \%)$ \\
\hline Lymphocytes $\times 10^{9} / \mathrm{L}$ & 185 & $1.5(1.1-2.05)$ \\
\hline Lymphocyte less than 1 & & $29(15.7 \%)$ \\
\hline Lymphocyte more than 3.6 & & $32(17.3 \%)$ \\
\hline Neutrophils $\times 10^{9}$ & 185 & $4.8(3.5-6.8)$ \\
\hline Neutrophils less than 1.8 & & $14(7.6 \%)$ \\
\hline more than 7.1 & & $64(34.6 \%)$ \\
\hline Platelets $\times 10^{9}$ & 185 & $214(178-252)$ \\
\hline Platelets Less than 100 & & $2(1.1 \%)$ \\
\hline C-reactive protein (CRP) (mg/L) & 124 & $4.5(1.1-14.6)$ \\
\hline $\mathrm{CRP}>8$ & & $46(37.1 \%)$ \\
\hline Procalcitonin (PCT) (ng/mL) & 108 & $0.05(0.05-0.08)$ \\
\hline $\mathrm{PCT}>0.2$ & & $12(11.1 \%)$ \\
\hline Aspartate aminotransferase (AST) (U/L) & 125 & $21(16-28)$ \\
\hline AST more than 40 & & $14(11.2 \%)$ \\
\hline Alanine aminotransferase (ALT) (U/L) & 149 & $13(11-24)$ \\
\hline ALT more than 40 & & $36(24.2 \%)$ \\
\hline Lactate dehydrogenase (LDH) (IU/L) & 121 & $181(154-222)$ \\
\hline LDH more> 200 & & $51(42.1 \%)$ \\
\hline D-Dimer (ng/mL) & 100 & $488.5(333-754.5)$ \\
\hline $500-1000$ & & $6(6 \%)$ \\
\hline$>1500$ & & $4(4 \%)$ \\
\hline Albumin (g/L) & 148 & $32(30-35)$ \\
\hline Albumin less than 30 & & $31(20.9 \%)$ \\
\hline Chest $\mathrm{x}$-ray diagnosis of pneumonia & 52 & $8(15.4 \%)$ \\
\hline
\end{tabular}

36 weeks, either spontaneous delivery or due to other obstetric causes.

A total of 167 neonates were delivered with two sets of twins. Seventy-nine (47.8\%) of neonates were born by cesarean section. Of these, one of the neonates was delivered by emergency cesarean due to maternal hypoxia as a result of worsening pneumonia, and the other 78 were due to either fetal distress or obstetrical indication. Median birth weight was 3006 g (IQR: 2750-3215), and only $5(3 \%)$ neonates required intubation and surfactant due to hyaline membrane disease of prematurity. Two (1.2\%) of the neonates tested positive for SARS-CoV-2 infection, and there was no neonatal death.

Clinical characteristics of SARS-CoV-2 positive neonates are shown in Table S3. The first positive neonate was born at 31 weeks by vaginal delivery; the mother presented with preterm premature rupture of membrane
Table 3 Maternal hospital treatment and outcomes

\begin{tabular}{ll}
\hline Characteristics & Number (\%) of patients \\
\hline Drug therapy: & $180(97.3 \%)$ \\
Oseltamivir & $2(1.1 \%)$ \\
Lopinavir-ritonavir & $45(24.3 \%)$ \\
Ceftriaxone & $5(2.7 \%)$ \\
Azithromycin & $179(96.7 \%)$ \\
low molecular weight heparin & $38(20.5 \%)$ \\
Antenatal steroid for lung maturation & $2(1.1 \%)$ \\
Intensive care unit (ICU) admission & 0 \\
ECMO & \\
Final outcomes: & 0 \\
Died & $185(100 \%)$ \\
Discharged & $15(14-22)$ \\
Length of hospital stay, days (median, IQR) & \\
\hline ECMO; extracorporeal membrane oxygenation &
\end{tabular}

and developed intrapartum fever $\left(38.2^{\circ} \mathrm{C}\right)$. The obstetrical cause of fever was ruled out, and the COVID-19 was suspected that was later confirmed on RT-PCR. The second positive neonate was born at 39 weeks' gestation by spontaneous vaginal delivery after $24 \mathrm{~h}$ of premature rupture of membrane. One newborn was asymptomatic from COVID-19 symptoms. The second newborn developed tachypnoea and increase work of breathing on day 4 of age and required humidified high flow nasal cannula for 5 days. The neonate's clinical condition improved, and a chest $\mathrm{x}$-ray showed complete resolution of the bilateral streaky lung infiltrate.

\section{Discussion}

This is a descriptive study on the maternal as well as neonatal clinical features and outcome of pregnancies complicated with SARS-CoV-2 infection. Thus far, the majority of the preliminary research articles report a small sample size $[12,13,15,18]$. This study is among the first to report COVID-positive maternal and neonatal clinical characteristics and outcomes with a comparatively large sample size.

In this study, 185 pregnant women were identified with confirmed SARS-CoV-2 infection with. Around $88 \%$ were symptomatic, with the most common symptom being fever in $58 \%$ of patients followed by cough in $50.6 \%$ of patients. These findings are in accordance with a number of preliminary studies $[14,15,18,29]$. A prospective cohort study using the United Kingdom Obstetric Surveillance System (UKOSS) found fever and cough as common symptoms in pregnant women having the diagnosis COVID-19 disease [29]. A systematic review revealed that the most dominant initial symptoms in pregnant women with COVID-19 were fever and cough [18]. Similarly, a retrospective study found that common 
Table 4 Pregnancy and neonatal outcomes

\begin{tabular}{|c|c|}
\hline Outcomes & Number (\%) of patients \\
\hline \multicolumn{2}{|l|}{ Pregnancy outcomes: } \\
\hline Continued pregnancy & $16(8.6 \%)$ \\
\hline Miscarriage & $3(1.6 \%)$ \\
\hline Intrauterine fetal death (IUFD) & $1(0.54 \%)$ \\
\hline Delivered live birth (including two twin birth) & $165(89 \%)$ \\
\hline \multicolumn{2}{|l|}{ Gestational age at delivery, weeks } \\
\hline Median (interquartile range) & $38(36-39)$ \\
\hline $27-32^{+6}$ weeks & $2(1.2 \%)$ \\
\hline $33-36^{+6}$ weeks & $42(25.5 \%)$ \\
\hline$\geq 37$ weeks & $121(73.3 \%)$ \\
\hline \multicolumn{2}{|l|}{ Mode of delivery } \\
\hline C-section & $79(47.8 \%)$ \\
\hline Elective (repeat/maternal request) & $35(44.3 \%)$ \\
\hline Emergency & $10(12.6 \%)$ \\
\hline Maternal Hypoxia & $1(1.2 \%)$ \\
\hline Preeclampsia & $11(13.9 \%)$ \\
\hline Failed induction/ failure to progress & $13(16.4 \%)$ \\
\hline Fetal distress & $9(11.4 \%)$ \\
\hline \multicolumn{2}{|l|}{ Type of anesthesia during C-section } \\
\hline - General & $9(11.4 \%)$ \\
\hline · Spinal & $70(88.6 \%)$ \\
\hline Vaginal delivery & $86(52.1 \%)$ \\
\hline Instrumental delivery & 0 \\
\hline Prolonged rupture of membrane (PROM>18 h) & $6(3.6 \%)$ \\
\hline Birth weight (grams), median (IQR) & $3006(2750-3215)$ \\
\hline Head circumference (cm), median (IQR) & $33(32-34.5)$ \\
\hline 1-min Apgar score, mean \pm (SD) & $8(1)$ \\
\hline 5-min Apgar score, mean \pm (SD) & $9(1)$ \\
\hline Neonatal death & 0 \\
\hline \multicolumn{2}{|l|}{ Neonates tested for SARS-CoV-2 infection } \\
\hline \multicolumn{2}{|l|}{ Positive for COVID-19 } \\
\hline None & $165(98.8 \%)$ \\
\hline Day 5 swab positive test & $2(1.2 \%)$ \\
\hline Day 14 swab positive & $1(0.6 \%)$ \\
\hline
\end{tabular}

symptoms in pregnant women in the wake of SARSCoV-2 infection are cough and fever, and less common symptoms include shortness of breath, diarrhea, and myalgia [13]. On the contrary, a study found the majority of women being asymptomatic and afebrile at presentation [17]. However, the majority of the studies have supported the evidence of fever and cough as the most common symptoms [14, 15, 30-35].

Data from the preliminary studies found that majority of pregnant women with COVID-19 were in the late second or third trimester [29]. In our study, the median gestational age on diagnosis was 29 weeks, and half of the women were in their 3rd trimester. Likewise, a prospective cohort study using UKOSS found that most women were hospitalized in the 3rd trimester [8, 29]. Moreover, in our study, $10 \%$ of the patients had gestational diabetes. Evidence of an association between gestational diabetes and pregnant women infected with SARS-CoV-2 is well documented [29].

With reference to the laboratory findings, in our study, $15.7 \%$ of the pregnant patients had lymphopenia, and elevated ALT and AST were observed in 24.2 and $11.2 \%$ 
of the patients, respectively, and $10 \%$ had elevated Ddimer. Several studies have reported lymphopenia in both the general population affected by COVID-19 [36] and also in pregnant women affected by COVID-19 [17, 37]. Similarly, a retrospective study found the likelihood of lymphopenia as well as increased concentrations of ALT or AST as one of the clinical manifestations [13]. Pregnancy is widely accepted as a hypercoagulable state [38], and monitoring of D-dimer is also necessary. A case series study has reported elevated D-dimer in pregnant women with COVID-19 and its association with increased mortality rate [39].

Preliminary studies on pregnancies complicated with SARS-CoV-2 infection suggested a low rate of admission to the ICU, maternal, and neonatal death [40]. Moreover, the rate of severe pneumonia in pregnant women was also not greater than the general population [41]. In our study, $15.4 \%$ had a radiological diagnosis of pneumonia, and only 2 patients required critical care for worsening respiratory conditions, which are in accordance with the preliminary records. A case series published by the clinicians in New York reported a similarly low rate of around 5\% of the pregnant patients with SARS-CoV-2 infection requiring critical care [14]. Likewise, a prospective cohort study using UKOSS reported that one woman per 2400 giving birth required critical care, and the maternal mortality rate was roughly about one in 18,000 women undergoing delivery [29].

The rates of ICU admission and mortality among pregnant women admitted to hospital with COVID-19 are proportional to the rates among the general population $[29,41]$. In our study, we found favorable outcomes among pregnant women with SARS-CoV-2 infection. Most of the patients had mild symptoms, with only a few ICU admissions and zero mortality. The clinical features of pregnant women with SARS-CoV-2 infection were similar to those of the general population having SARS-CoV-2 infection, as reported in previous studies [42].

In our study, $26.6 \%$ of neonates were born preterm, and $47.8 \%$ of neonates were delivered by cesarean section. These findings are supported by similar findings in the past, in the data from the UKOSS study, where 59\% of the neonates had cesarean births, and $27 \%$ had preterm births [29]. Another study reported that the majority of pregnant women had a cesarean section planned delivery to prevent neonatal transmission of the virus [34]. Similarly, a systematic review finds out that the frequent mode of delivery in cases reported was cesarean section [18].

Newborns born to SARS-CoV-2 infected mothers are most likely to be asymptomatic [12]. Similarly, in our study, $73.3 \%$ of the neonates, born full-term, were asymptomatic. The findings of our study propose that neonatal outcome is reassuring, keeping with other studies [29, 43-46]. However, in our study, two neonates tested positive for COVID-19 on day 5 of nasopharyngeal swab testing. According to Shah's classification, the diagnosis of congenital or intrapartum infection could not be confirmed [47]. Some studies from the past reported inconsistency with no evidence of vertical transmission [13, 34]. Nevertheless, vertically acquired infection is still reasonable and cannot be ruled out as supported by preliminary studies and emerging evidence [8]. Further investigations around the vertical transmission of SARS-CoV-2 infections are needed.

In our study, the mothers of two COVID-19-positive neonates presented with preterm premature rupture of membrane (PROM). PROM is known to be linked to neonatal sepsis, and duration of PROM and viral infection in neonate, especially with herpes simplex and HIV, is well documented, however, it is difficult to make a definitive conclusion here $[48,49]$.

A major strength of this study is its large sample size, whereas preliminary studies $[12,15,18]$ were comprised of small sample size of 10-84 pregnant women and could not draw a firm conclusion. The findings of the study may aid clinicians and patients in the effective management of the pregnancies complicated with SARS$\mathrm{CoV}-2$ infection. However, there are also some inherent limitations to this study due to its retrospective study design.

\section{Conclusions}

In this national-based study from Kuwait, the majority of the pregnant women with SARS-CoV-2 infection had mild symptoms with no severe illness. Mother-to-child vertical transmission of SARS-CoV-2 is possible; however, the impacts of COVID-19 infection during pregnancy on maternal and neonatal outcomes do not appear to be unfavorable. Further studies are required to evaluate long-term outcomes and potential vertical transmission of SARS-CoV-2 to infants.

\section{Supplementary Information}

Supplementary information accompanies this paper at https://doi.org/10. 1186/s12884-020-03461-2.

Additional file 1. Management of patients with COVID-19.

Additional file 2: Table S1. Clinical features of pregnant patients with COVID-19 in ICU. Table S2. Clinical features of pregnant COVID-19 patients who had a miscarriage. Table S3. Clinical features of COVID-19 positive neonate.

\section{Abbreviations}

RT-PCR: Real-time reversetranscriptasepolymerasechainreaction; MERS: Middle East Respiratory Syndrome; SARS: Severe Acute Respiratory Syndrome;

ARDS: Acute respiratory distress syndrome; qSOFA: Quick Sequential Failure Assessment; CRP: C-reactive protein; PIH: Pregnancy-induced hypertension; ICU: Intensive care unit; PROM: Premature rupture of membrane 


\section{Acknowledgements}

We thank Dr. Waleed Al-Jassar from the Obstetrics and Gynaecology department, Faculty of medicine (Kuwait University) for the helpful edits on the manuscript.

\section{Authors' contributions}

AA, WAF, MH, MAL, MAY, and AAI conceptualized \& planned the study, drafted the proposal and manuscript, planned and oversaw data collection, revised the manuscript. $A E, A B$ and $A A H$ collected the data and helped in drafting the manuscript as well. All the authors have ready and accepted the manuscript for publication.

\section{Funding}

Research grant funded by the Kuwait Foundation for the Advancement of Science.

\section{Availability of data and materials}

The datasets used and/or analyzed during the current study are available from the corresponding author on reasonable request.

\section{Ethics approval and consent to participate}

The study was approved by the Ethical Committee of the Ministry of Health of Kuwait (2020/1420). Administrative permissions were approved by the department of Planning and Quality Affair (Ministry of Health of Kuwait) and the respective register holders; Maternal and Perinatal COVID-19 Kuwait National Registry.

\section{Consent for publication}

Not applicable.

\section{Competing interests}

The authors declare that they have no competing interests.

\section{Author details}

'Obstetrics and Gynecology Department, Farwaniya Hospital, Sabah Al Nasser, Kuwait. ${ }^{2}$ Paediatric Department, Farwaniya Hospital, Sabah Al Nasser, Kuwait. ${ }^{3}$ Department of Microbiology, Faculty of Medicine, Kuwait University, Jabriya, Kuwait. ${ }^{4}$ Paediatrics Department, Faculty of Medicine, Kuwait University, Jabriya, Kuwait. ${ }^{5}$ Neonatal Department, Maternity Hospital, Kuwait City, Kuwait. ${ }^{6}$ Obstetrics and Gynaecology Department, Al-Adan Hospital, Hadiya, Kuwait. ${ }^{7}$ Neonatal Department, Farwaniya Hospital, Subah An Nasser, 81400 Kuwait City, Kuwait.

Received: 11 August 2020 Accepted: 26 November 2020 Published online: 02 December 2020

\section{References}

1. World Health Organization. Novel coronavirus situation report-2. 2020 https://www.who.int/docs/default-source/coronaviruse/situation-reports/202 00122-sitrep-2-2019-ncov. Accessed.

2. Centers for Disease Control and Prevention. First travel-related case of 2019 novel coronavirus detected in United States, January 21st, 2020. https:// www.cdc.gov/media/releases/2020/p0121-novel-coronavirus-travel-case.htm. Accessed 5 July 2020.

3. European Centre for Disease Prevention and Control. Novel coronavirus in China. https://www.ecdc.europa.eu/en/novel-coronavirus-china. Accessed 5 July 2020

4. Singhal T. A review of coronavirus Disease-2019 (COVID-19). Indian J Pediatr. 2020:87:281-6.

5. Fan C, Lei D, Fang C, Li C, Wang M, Liu Y, et al. Perinatal Transmission of COVID-19 Associated SARS-CoV-2: Should We Worry? Clin Infect Dis. 2020; ciaa226. https://doi.org/10.1093/cid/ciaa226.

6. Zhou F, Yu T, Du R, Fan G, Liu Y, Liu Z, et al. Clinical course and risk factors for mortality of adult inpatients with COVID-19 in Wuhan, China: a retrospective cohort study. Lancet. 2020;395:p1054-p106

7. Mor G, Cardenas I. The immune system in pregnancy: a unique complexity. Am J Reprod Immunol. 2010;63:425-33.

8. Coronavirus infection and pregnancy. The Royal College of Obstetricians and Gynaecologists. 2020. https://www.rcog.org.uk/en/guidelines-researchservices/guidelines/coronavirus-pregnancy/covid-19-virus-infection-andpregnancy/. Accessed 5 July 2020.
9. Docherty $A B$, Harrison EM, Green CA, et al. Features of 20133 UK patients in hospital with covid-19 using the ISARIC WHO Clinical Characterisation Protocol: prospective observational cohort study. BMJ. 2020;369:m1985.

10. ICNARC. Report on COVID-19 in critical care. 2020. https://www.icnarc.org/ Our-Audit/Latest-News/2020/04/10/Report-On-5578-Patients-Critically-IIIWith-Covid-19. Accessed 1 Jun 2020.

11. Chen Y, Li Z, Zhang YY, Zhao WH, Yu ZY. Maternal health care management during the outbreak of coronavirus disease 2019. J Med Virol. 2020;92:731-9.

12. Zhu H, Wang L, Fang C, Peng S, Zhang L, Chang G, et al. Clinical analysis of 10 neonates born to mothers with 2019-nCoVpneumonia. Transl Pediatr. 2020;9:51-60.

13. Chen H, Guo J, Wang C, Luo F, Yu X, Zhang W, et al. Clinical characteristics and intrauterine vertical transmission potential of COVID-19 infection in nine pregnant women: a retrospective review of medical records. Lancet. 2020;395:809-15.

14. Breslin N, Baptiste C, Gyamfi-Bannerman C, Miller R, Martinez R, Bernstein K, et al. COVID-19 infection among asymptomatic and symptomatic pregnant women: two weeks of confirmed presentations to an affiliated pair of New York City hospitals. Am J Obstet Gynecol MFM. 2020;2:100118.

15. Chen L, Li Q, Zheng D, Zhao Y, Qiao J. Clinical characteristics of pregnant women with covid-19 in Wuhan, China. N Engl J Med. 2020;382:e100.

16. Pierce-Williams RAM, Burd J, Felder L, Khoury R, Bernstein PS, Avila K, et al. Clinical course of severe and critical COVID-19 in hospitalized pregnancies: a US cohort study. Am J Obstet Gynecol MFM. 2020;2(3):100134.

17. Smith V, Seo D, Warty R, Payne O, Salih M, Chin KL, et al. Maternal and neonatal outcomes associated with COVID-19 infection: a systematic review. Plos One. 2020;15:e0234187.

18. Muhidin S, Behboodi Moghadam Z, Vizheh M. Analysis of maternal coronavirus infections and neonates born to mothers with 2019-nCoV; a systematic review. Arch Acad Emerg Med. 2020;8:e49.

19. Rasmussen SA, Smulian JC, Lednicky JA, Wen TS, Jamieson DJ. Coronavirus disease 2019 (COVID-19) and pregnancy: what obstetricians need to know. Am J Obstet Gynecol. 2020;222:P415-26.

20. Schwartz DA, Graham AL. Potential maternal and infant outcomes from (Wuhan) coronavirus 2019-nCoV infecting pregnant women: lessons from SARS, MERS, and other human coronavirus infections. Viruses. 2020:12:194.

21. Jamieson DJ, Honein MA, Rasmussen SA, Williams JL, Swerdlow DL, Biggerstaff MS, et al. H1N1 2009 influenza virus infection during pregnancy in the USA. Lancet. 2009;374:451-8.

22. Siston AM, Rasmussen SA, Honein MA, Fry AM, Seib K, Callaghan WM, et al. Pandemic 2009 influenza a (H1N1) virus illness among pregnant women in the United States. JAMA. 2010;303:1517-25.

23. Australian and New Zealand Intensive Care Inlfuenza Investigators and the Australian Maternity Outcomes Surveillance System. Critical illness due to 2009 A/H1N1 influenza in pregnant and postpartum women: population based cohort study. BMJ. 2010;340:c127

24. Mullins E, Evans D, Viner RM, O'Brien P, Morris E. Coronavirus in pregnancy and delivery: rapid review. Ultrasound Obstet Gynecol. 2020;55:586-92.

25. Alfaraj SH, Al-Tawfiq JA, Memish ZA. Middle East respiratory syndrome coronavirus (MERS-CoV) infection during pregnancy: report of two cases \& review of the literature. J Microbiol Immunol Infect. 2019;52:501-3.

26. Yang P, Wang X, Liu P, Wei C, He B, Zheng J, et al. Clinical characteristics and risk assessment of newborns born to mothers with COVID-19. J ClinVirol. 2020;127:104356.

27. Stuebe A. Should infants be separated from mothers with COVID-19? First, Do No Harm. Breastfeed Med. 2020;15:351-2.

28. Ranieri VM, Rubenfeld GD, Thompson BT, Ferguson ND, Cladwell E, Fan E, et al. Acute respiratory distress syndrome: the Berlin definitions. JAMA. 2012; 307:2526-33.

29. Knight M, Bunch K, Vousden N, Morris E, Simpson N, Gale C, et al. Characteristics and outcomes of pregnant women admitted to hospital with confirmed SARS-CoV-2 infection in UK: national population based cohort study. BMJ. 2020;369:m2107

30. Zhang $L$, Jiang $Y$, Wei M, Cheng BH, Zhou XC, Li J, et al. Analysis of the pregnancy outcomes in pregnant women with covid-19 in Hubei Province. Zhonghua Fu Chan KeZaZhi. 2020;55:166-71.

31. Breslin N, Baptiste C, Miller R, Fuchs K, Goffman D, Gyamfi-Bannerman C, et al. Covid-19 in pregnancy: early lessons. Am J Obstet Gynecol. 2020;2: 100111.

32. Liu $Y$, Chen $H$, Tang $K$, Guo $Y$. Clinical manifestations and outcome of SARSCoV-2 infection during pregnancy. J Infect. 2020;4453(2):30109-2. 
33. Juusela A, Nazir M, Gimovsky M. Two cases of coronavirus 2019-related cardiomyopathy in pregnancy. Am J Obstet Gynecol MFM. 2020;2:100113.

34. Juan J, Gil MM, Rong Z, Zhang Y, Yang H, Poon LC. Effects of coronavirus disease 2019 (COVID-19) on maternal, perinatal and neonatal outcomes: a systematic review. Ultrasound Obstet Gynecol. 2020;56:15-27.

35. Public Health England. COVID-19: investigation and initial clinical management of possible cases. 2020. https://www.gov.uk/ government/ publications/ wuhan-novel-coronavirus-initial investigation-of-possiblecases/investigation-and-initial-clinical-management-of-possible-cases-ofwuhannovel-coronavirus-wn-cov-infection. Accessed 1 June 2020.

36. Yang H, Hu B, Zhan S, Yang L. Effects of SARS-CoV-2 infection on pregnant women and their infants: a retrospective study in Wuhan, China. Arch Pathol Lab Med. 2020;144(10):1217-22.

37. Shi L, Wang Y, Yang H, Duan G, Wang Y. Laboratory Abnormalities in Pregnant Women with Novel Coronavirus Disease 2019. Am J Perinatol. 2020;37(10):1070-3.

38. Bremme KA. Haemostatic changes in pregnancy. Best Pract Res Clin Haematol. 2003;16:153-68.

39. Lokken EM, Walker CL, Delaney S, Kachikis A, Kretzer NM, Erickson A, Resnick $R$, et al. Clinical characteristics of 46 pregnant women with a SARS-CoV-2 infection in Washington state. Am J Obstetr Gynecol. 2020;223(6):911.e1911.e14.

40. Zaigham M, Andersson O. Maternal and perinatal outcomes with COVID-19: a systematic review of 108 pregnancies. Actaobstetricia et gynecologica Scandinavica. 2020;99(7):823-9.

41. Yan J, Guo J, Fan C, Juan J, Yu X, Li J, et al. Coronavirus disease 2019 (COVID-19) in pregnant women: a report based on 116 cases. Am J Obstetr Gynecol. 2020;223(1):111.e1-111.e14.

42. Huang C, Wang Y, Li X, Ren L, Zhao J, Hu J, et al. Clinical features of patients infected with 2019 novel coronavirus in Wuhan, China. Lancet. 2020;395: 497-506.

43. Yu N, Li W, Kang Q, Xiong Z, Wang S, Lin X, et al. Clinical features and obstetric and neonatal outcomes of pregnant patients with COVID-19 in Wuhan, China: a retrospective, single-Centre, descriptive study. Lancet Infect Dis. 2020;20:559-64.

44. Zeng H, Xu C, Fan J, Tang Y, Deng Q, Zhang W, et al. Antibodies in infants born to mothers with covid-19 pneumonia. JAMA. 2020;323:1848-9.

45. Zeng L, Xia S, Yuan W, Yan K, Xiao F, Shao J, et al. Neonatal early-onset infection with SARS-CoV-2 in 33 neonates born to mothers with covid-19 in Wuhan, China. JAMA Pediatr. 2020;174(7):722-5.

46. Dong L, Tian J, He S, Zhu C, Wang J, Liu C, et al. Possible vertical transmission of SARSCOV-2 from an infected mother to her newborn. JAMA. 2020;323(18):1846-8.

47. Shah PS, Diambomba Y, Acharya G, Morris SK, Bitnun A. Classification system and case definition for SARS-CoV-2 infection in pregnant women, fetuses, and neonates. Acta Obstetriciaet Gynecol Scandinavica. 2020;99: $565-8$.

48. Boskabadi H, Maamouri G, Mafinejad S. Neonatal complications related with prolonged rupture of membranes. Macedonian J Med Sci. 2011;4:93-8.

49. Simonsen KA, Anderson-Berry AL, Delair SF, Davies HD. Early-onset neonatal sepsis. Clin Microbiol Rev. 2014;27:21-47.

\section{Publisher's Note}

Springer Nature remains neutral with regard to jurisdictional claims in published maps and institutional affiliations.

Ready to submit your research? Choose BMC and benefit from:

- fast, convenient online submission

- thorough peer review by experienced researchers in your field

- rapid publication on acceptance

- support for research data, including large and complex data types

- gold Open Access which fosters wider collaboration and increased citations

- maximum visibility for your research: over $100 \mathrm{M}$ website views per year

At BMC, research is always in progress.

Learn more biomedcentral.com/submissions 